8. The paratyphoid bacillus (A or $B$ ) is frequently isolable from the fæces, but in many cases not until after the symptoms have subsided; one negative finding should not be accepted as conclusive. It is also occasionally isolable from the blood, urine, and from metastatic abscesses.

9. Distinct help in diagnosis is obtainable from repeated quantitative Widal reactions, but much experience is required for their interpretation, and they must be read in conjunction with the clinical evidence and with the history of previous inoculation.

10. On the assumption that this disease is of the enteric group, the same precautions as in the case of true typhoid fever are indicated against its spread. In particular, carriers must be watched, for bacilli may be present in their urine and fæces after all symptoms of illness have subsided.

\section{THE EXPLANATION OF A RECTO- URETHRAL ANOMALY, AND SOME POINTS IN NORMAL ANATOMY.}

\section{BY FREDERIC WOOD JONES, D.Sc., M.B.,} B.S. LOND.,

PROFESSOR OF ANATOMY IN THE LONDON SCHOOL OF MHDICINE FOR WOMEN.

AMoNG the many conditions of congenital mal. formation met with in connexion with the termination of the hind gut there is one which, though perhaps of but minor surgical importance, is nevertheless a most interesting anomaly that has never received any adequate explanation. That the hind gut may open into the urinary tract at various levels is, of course, well known; rectal openings into the prostatic urethra are almost the rule in cases of imperforate rectum. Various other recto-urethral communications occur in the two sexes, and all of these conditions are, I think, satisfactorily explained by appealing to the development of the terminal portion of the hind gut.

But the condition I am dealing with is in different case, for no described phase in rectal or urethral development throws any light upon the causation of the malformation. This anomaly is well known, is not very rare, and is described in most surgical text-books; briefly it is that in which the rectal orifice is carried forwards in the male perineum to open in the neighbourhood of the frænulum of the glans penis. Keith ${ }^{1}$ has dealt with some of the factors underlying this condition and many clinicians have recorded cases of the malformation; yet I do not think that one may say that the ontogeny or the phylogeny of the anomaly has been explained. In attempting its explanation I have been guided by two facts: the first that there are other malformations obviously akin to this one, and the second that some points in the normal anatomy of the parts involved present more interest than is usually imagined. These two considerations are my excuse for publication.

In attempting any explanation it is necessary to go back to an early stage of human development, the stage when an ectodermal invagination - the cloaca or proctodeum-dimples the hind

1. Malformations of the Hind End of the Body, Brit. Med. Jour., December, 1938 . end of the embryo over the site of the termina. tion of the endodermal internal visceral canals. From these endodermal canals the ectodermal cloaca is separated by the cloacal membrane, which, by the subsequent separation of the endo. dermal urogenital and rectal passages, becomes subdivided into a ventral urogenital membrane and a dorsal anal membrane. Within the ecto. dermal cloaca is developed the copulatory organ as a primarily bilateral thickening of its ventral wall. It is in the characters of this copulatory organ that the explanation of the development of this malformation must be sought.

It has often been noted that the embryonic stages of the human copulatory organ find a -very exact parallel in the adult organ of the imbricated reptiles, such as the tortoises and turtles. This comparison is by no means a forced one, and the examination of the extremely large and well-marked cloacal structures of such a form as Testudo elephantina makes the interpretation of the minute and slightly marked human embryonic structures more easy. (Fig. 1.) The copulatory organ of this giant tortoise is composed of bilateral erectile thickenings of the ventral cloacal wall (corpora cavernosa); upon their free (dorsal) aspect are developed outstanding folds seminal guides-having in their attached margins other erectile masses (corpora spongiosa). Between these two seminal guides runs a median groove-the seminal groove-converted into a closed seminal canal only during functional activity by the erection and meeting of the seminal guides. The seminal groove runs from the base of the glans to the opening of the urogenital sinus; the seminal guides also start at the same point on the distal extremity of the penis,
FIG. 1.

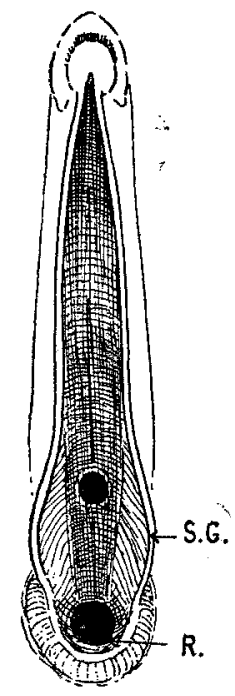

The copulatory organ of Testudo elephan. tina, showing the semial guide (S.G.) passing into the rectal orifice (R.). This is a nor onic condition. but they run past the urogenital sinus orifice and strangely enough terminate within and around the sides of the rectal opening. It is for this reason that in comparative anatomy these folds are known as the plice recto. urethrales, but in the terminology of human development they are merely named the "inner genital folds." These inner genital folds of human embryology are something more than mere frills in the male tortoise, for they are functioning male sexual structures whose office is to close temporarily the seminal canal and so carry the sexual products to the top of the copulatory organ. Their office is exactly the same in man, and it is effected by their permanent closure during embryonic life. In the reptilian female these folds are functionless, and they are reduced; in the human female they are also in a rudimentary condition and appear as the labia minora.

Now, in the human embryo, just as in the tortoise, these seminal guides or inner genital folds consist of two elements-a mass of cavernous erectile tissue and a free frill-like skin-covered edge. In the male the erectile tissue is represented by the whole of the corpus spongiosum which, extending backwards as the "bulb," abuts against the anterior margin of the terminal part of 
the rectum. The free edges are represented, coalesced, in the median raphé, and the limits of this raphé present the greatest interest. In the male human embryo, just as in the male tortoise, the free edges of the seminal guides extend from the base of the glans, at the site of the frænulum, and pass backwards right into the anal margin. The adult raphé is present over the same area. It seems a most remarkable instance of conservatism that these folds should pass into the human anal orifice just as they do in the chelonian reptiles. In the human female the erectile masses of the seminal guides are rudimentary and variable in development, and they constitute the "bulbs of the vestibule." The free edges of the seminal guides form the labia minora, and these rudimentary structures are again very variable in development. Being functionless and rudimentary structures associated in the sexual complex it is but natural that their development should be inconstant, and the gynæcologist will see in this inconstancy the solution of the mystery that surrounds the presence and the basis of the fourchette:

I do not think it is very common for the labia minora to extend so far back as to meet quite definitely behind the vaginal orifice; it is certainly very abnormal for them to extend any further back than this point. This means that there is of necessity a very curious sexual distinction between the male and female anal orifice, for in the male purely sexual structures (the seminal guides) normally pass within its margin as the median raphé, whilst in the female this element is altogether absent. This point has apparently escaped the notice of anatomists, but it is an
FIG. 2.

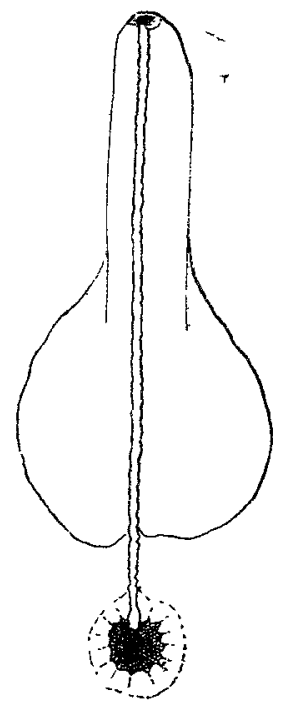

The normal distribu* tion of the median raphinal guides) in the male. Note the papilla marking the into the anal mar. gin. possibly more than fusion not only affects that portion forming the normal medianraphé, but also that part which runs around the anal margin. The anus is thereby closed in and embraced in the raphé (just as it would be if the seminal guides of the male tortoise were to coalesce), and the anal orifice is carried forward in the raphé to its termination passage of the raphé in the frænulum. (Fig. 3.) It may fall short of the frænulum and fistulous openings may be present anywhere in the normal extent of the raphé.

Another anomalous condition may arise obviously as a modification of the process described. The median raphé may be formed right across the anal membrane and the membrane may subsequently perforate upon both sides of the raphé, leaving it as a median band this malformation is a wellknown one.

Since this backward extension of the seminal guides is typically a male peculiarity, it is obvious that this anomaly cannot be present with the external genitalia typical of the human female; and yet Keith was able to record six specimens of a female malformation which is obviously akin to it. These six cases resemble each other exactly ; all of them are females, with a male type of external genitalia. All of them, we may be sure, though females in other respects, had the seminal guides abnorm. ally developed, and the closing of these guides, after the fashion normal in the male, led to the closure of the anus and the prolongation of the rectal opening into the vulva and "penile"

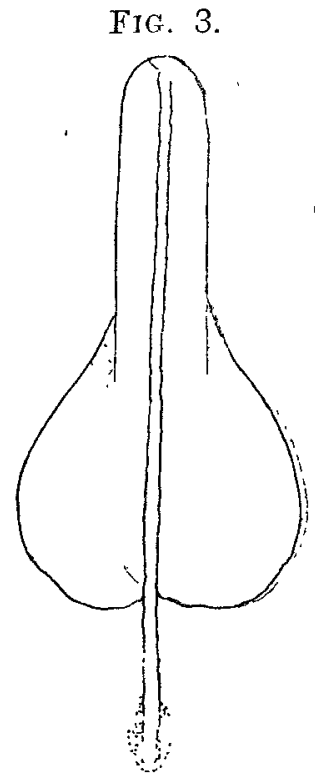

Malformation in which the anal portion of the seminal guides has fused, obliterating the anus and carrying the rectal opening forwards in the raphé. stretching across the anal orifice; urethra. In the females of some monkeys the seminal guides (labia minora, normally coalesce and make a urethra in the clitoris; in these abnormal human females they have taken on a further and more masculine derelopment and have embraced the anal orifice, just as they do in some abnormal males. London School of Medicine for Women.

Removal of Warsaw University Medical CLASSES. - The request of the directors of the Warsaw University for the use of the Moscow University auditorium and clinic in the evenings for the Warsaw medical students, has been refused by the directors of the Moscow University on the ground that the latter is already overcharged with students. Therefore the Warsaw University authorities are looking for accommodation at Saratoff and Rost off on the Don, at both of which accommodation has been offered to them.

The Relief of "Alien Enemies." - The third report of the Emergency Committee for the Assistance of Germans, Austrians, and Hungarians in Distress is a document of which the Religious Society of Friends, under whose auspices the committee was convened, may be proud. From. the initiation of its work in August, 1914, up to June, 1915, over 3250 applications for grants towards maintenance have been investigated and the majority of the applicants helped with money or clothing. Much of the work of the committee has been done at the request of the Home Office, particularly where subsidiary travelling expenses or arvire were necessary. There are now in this country over 30,000 civilian prisoners and a large number of military prisoners housed in 22 camps in different parts of the British Isles. For many of these persons generous grants of clothing have been made and materials supplied for handicraft and educational work. A very useful feature of the committee's work is the assistance which is given to British-born wives and alien children who require convalescent accommodation. The committee express their gratitude for the generous professional help of Dr. D. M. Barcroft, Dr. R. Fortescue Fox, Dr. J. Tylor Fox, and Dr. Sara E. White. Subscriptions should be sent to the secretary, Aliens' Relief Fund, 169, St. Stephen's House, Westminster Bıidge, S.W. 